\title{
Environmental Novelty Differentially Affects c-fos mRNA Expression Induced by Amphetamine or Cocaine in Subregions of the Bed Nucleus of the Stria Terminalis and Amygdala
}

\author{
Heidi E. W. Day, ${ }^{1,3}$ Aldo Badiani,2,4 Jason M. Uslaner, ${ }^{2}$ Matthew M. Oates, ${ }^{2}$ Nicole M. Vittoz, ${ }^{2}$ \\ Terry E. Robinson, ${ }^{2}$ Stanley J. Watson $\mathrm{Jr}^{1}{ }^{1}$ and Huda Akil ${ }^{1}$ \\ ${ }^{1}$ Mental Health Research Institute and 2 Psychology Department, University of Michigan, Ann Arbor, Michigan 48109, \\ ${ }^{3}$ Psychology Department, University of Colorado, Boulder, Colorado 80309, and ${ }^{4}$ Department of Human Physiology and \\ Pharmacology, University of Rome "La Sapienza", 00185 Rome, Italy
}

The environmental context in which amphetamine or cocaine are administered modulates both their acute psychomotor activating effects and their ability to induce sensitization. Here we report that environmental context differentially affects patterns of amphetamine- and cocaine-induced c-fos mRNA expression in the bed nucleus of the stria terminalis (BST) and amygdala of male rats.

In the medial amygdala and medial posterior BST, exposure to novelty resulted in a marked increase in c-fos mRNA. Amphetamine given at home did not induce c-fos mRNA, and when given in the novel environment, did not increase levels beyond that observed for novelty alone. In the basolateral and lateral amygdala, amphetamine or cocaine at home or exposure to novelty induced c-fos mRNA. When amphetamine or cocaine was given in a novel environment the c-fos mRNA response was significantly enhanced. In the central nucleus of the amyg-

The behavioral and subjective effects of addictive drugs, such as amphetamine or cocaine, are powerfully modulated by the psychological state of the organism and the context in which drugs are taken (Falk and Feingold, 1987). This is apparent even using a relatively simple animal model, in which the same dose of drug is administered to two groups of rats in physically identical environments. For one group, the environment is the home cage, whereas for the other group, the environment is completely novel. In this situation, both the acute psychomotor activating effects and the propensity of these effects to sensitize are greater when psychostimulants are given in association with environmental novelty (Badiani et al., 1995a,b; Crombag et al., 1996).

The neurobiological mechanisms by which the pharmacological effects of psychostimulants interact with environmental context are not clear. Environmental context has no effect on plasma or striatal levels of amphetamine (Badiani et al., 1997), suggesting that pharmacokinetic factors are not involved. The primary neuropharmacological effect of psychostimulants is to increase dopa-

Received July 3, 2000; revised Nov. 1, 2000; accepted Nov. 2, 2000.

This work was supported by National Institute of Mental Health Grants PO1MH42251 (H.A., S.J.W.) and DA04294 (T.E.R.). We thank Sharon Burke and Michelle M. Ostrander (University of Michigan) for their technical expertise and input and Dr. Serge Campeau (University of Colorado) for valuable discussion and support.

Correspondence should be addressed: Heidi E. W. Day at her present address: Psychology Department, Muenzinger Building, P.O. Box 345, Boulder, CO 803090345. E-mail: heididay@psych.colorado.edu.

Copyright (C) 2001 Society for Neuroscience $\quad 0270-6474 / 01 / 210732-09 \$ 15.00 / 0$ dala (CEA) and oval subnucleus of the BST (BSTov), amphetamine administration at home produced a robust increase in c-fos mRNA expression, whereas exposure to novelty had little effect. In contrast to other brain regions examined, the c-fos mRNA response to amphetamine in a novel versus home environment was significantly smaller. In both "home" and "novel" amphetamine groups, c-fos mRNA in the BSTov and CEA was predominantly expressed in enkephalin-containing cells; coexpression with corticotropin-releasing hormone was rare.

These data suggest that the context in which psychostimulants are given powerfully and differentially alters the response of limbic structures that have been functionally implicated in drug reinforcement and emotional behaviors.

Key words: amphetamine; cocaine; novelty; environment; cfos; amygdala; bed nucleus of the stria terminalis; dopamine

mine (DA) efflux in the caudate putamen (CP) and nucleus accumbens (ACB) (Wise and Bozarth, 1987). However, exposure to a novel environment does not alter amphetamine-induced DA release in these areas (Badiani et al., 1998, 2000), suggesting that another mechanism is involved.

In an attempt to delineate the neural circuitry potentially engaged by this interaction, we have investigated the expression of $c$-fos mRNA after an intraperitoneal injection of amphetamine or saline in a home versus novel environment. We have previously reported that in a number of forebrain regions, including the $\mathrm{CP}$ and $\mathrm{ACB}$, exposure to novelty enhances amphetamine-induced c-fos mRNA expression (Badiani et al., 1998). We also found, using a dual in situ hybridization (ISH) technique to study amphetamine-induced c-fos mRNA expression in D1 versus D2 DA receptor mRNA containing cells of the striatum, that the combination of amphetamine and novelty not only produced greater c-fos mRNA expression, relative to amphetamine or novelty alone, but recruited additional neural circuitry (Badiani et al., 1999).

However, evidence suggests the involvement of structures such as the extended amygdala in mediating the behavioral effects of psychostimulants (Alheid and Heimer, 1988). These limbic regions are thought to be important in stress and emotional responses, and thus are potential sites where psychostimulant drugs and environmental stimuli may interact. Previous studies have indicated that exposure to novelty (Emmert and Herman, 1999) or acute administration of psychostimulants (Umino et al., 1995; 
Engber et al., 1998) induces Fos expression in distinct regions of the amygdala. In the current study, we have used semiquantitative ISH to compare the effect of amphetamine, cocaine, or saline administration in a home versus novel environment on c-fos mRNA expression, in the amygdala and bed nucleus of the stria terminalis (BST) of male rats. The data indicate that the ability of amphetamine or cocaine to engage different subregions of the amygdala and BST is powerfully and differentially modulated by the context in which they are given.

\section{MATERIALS AND METHODS}

\section{Experiment 1}

Details of the experimental protocol have been described previously (Badiani et al., 1998). Briefly, male Sprague Dawley rats (Harlan Sprague Dawley, Indianapolis, IN), weighing 200-225 gm at the time of arrival were housed in standard stainless steel cages in a temperature- and humidity-controlled environment. Rats were maintained on a 14:10 hr light/dark cycle (lights on 6:00 A.M.) and were allowed ad libitum access to food and water throughout the experiment. Animals were acclimated to these housing conditions for 1 week before any experimental manipulation.

6-Hydroxydopamine lesion. All rats received a unilateral 6-hydroxydopamine (6-OHDA) lesion of the mesostriatal dopamine system, with left and right sides counterbalanced, as previously described (Robinson, 1984). This provided a way to quantify the psychomotoractivating effects of amphetamine by measuring amphetamine-induced rotational behavior. To protect noradrenergic terminals, desipramine hydrochloride $(15 \mathrm{mg} / \mathrm{kg}$, i.p.) was administered before induction of anesthesia. After a $10 \mathrm{~d}$ recovery period, apomorphine $(0.05 \mathrm{mg} / \mathrm{kg}$, s.c.) was administered to assess the development of DA receptor supersensitivity, as indicated by contraversive rotational behavior. Animals that made less than eight full rotations in a 2 min test period were excluded from the study.

Administration of amphetamine. Four days after the apomorphine screen, three groups of rats were housed in opaque plastic cylindrical cages. After $7 \mathrm{~d}$ of acclimation to the new home cage environment, animals were given an injection of saline vehicle intraperitoneally (homesaline; $n=9), 2.0 \mathrm{mg} \cdot \mathrm{kg}^{-1} \cdot \mathrm{ml}^{-1}$ D-amphetamine intraperitoneally (home-amphetamine; $n=12$ ) or remained untreated (untreated; $n=7$ ). Two additional groups of rats, which had been housed continuously in stainless steel hanging cages, were transported from the colony room to the cylindrical cages, which for them was a completely novel environment. They were then immediately given an injection of saline intraperitoneally (novel-saline; $n=9$ ) or $2.0 . \mathrm{mg} \cdot \mathrm{kg}^{-1} \cdot \mathrm{ml}^{-1} \mathrm{D}$-amphetamine intraperitoneally (novel-amphetamine; $n=11$ ). All injections were given between 12:00 and 1:00 P.M. Rotational behavior was videotaped remotely, and the number of full rotations made by the animal during the session were subsequently analyzed by an observer blind to the experimental group. Animals were killed by rapid decapitation 50 min after injection. Untreated rats were killed at this time also. Brains were removed and frozen in isopentane cooled to -40 to $-50^{\circ} \mathrm{C}$ and stored at $-80^{\circ} \mathrm{C}$. Coronal sections $(10 \mu \mathrm{m})$ were cut on a cryostat (Bright, Huntingdon, UK) at $200 \mu \mathrm{m}$ intervals through the BST and amygdala and mounted onto polylysine-coated slides. Sections were air-dried and stored at $-80^{\circ} \mathrm{C}$ until processing for in situ hybridization.

\section{Experiment 2}

For dual in situ hybridization experiments, the above protocol was repeated, using two groups of rats only: home-amphetamine $(n=8)$ and novel-amphetamine $(n=8)$.

\section{Experiment 3}

Because the 6-OHDA lesion sustained in the first two experiments could potentially influence the c-fos mRNA expression, the experiment was repeated, with minor modifications, in neurologically intact animals. In addition, the effect of cocaine on the amygdala c-fos mRNA response was investigated. Fifty-six male Sprague Dawley rats (Harlan) weighing 200$250 \mathrm{gm}$ were initially housed in stainless steel hanging cages in a temperature- and humidity-controlled environment. The rats were kept on a 14:10 hr light/dark cycle (lights on at 7:00 A.M.) and were given food and water ad libitum. The animals were kept in the colony room for $7 \mathrm{~d}$ before any experimental manipulation. Rats were then assigned to seven groups. Four groups were housed in $16 \times 10 \times 8$ inch white plastic tubs with ground corn cob bedding on the floor. Ten days later at 12:00 P.M., the rats either received saline $(1 \mathrm{ml} / \mathrm{kg}$, i.p.; home-saline; $n=5)$, amphetamine $\left(1.5 \mathrm{mg} \cdot \mathrm{kg}^{-1} \cdot \mathrm{ml}^{-1}\right.$, i.p.; home-amphetamine; $\left.n=9\right)$, cocaine $\mathrm{HCl}\left(15 \mathrm{mg} \cdot \mathrm{kg}^{-1} \cdot \mathrm{ml}^{-1}\right.$, i.p.; home-cocaine; $\left.n=9\right)$ in these chambers or were left undisturbed (untreated; $n=4$ ). The three remaining groups were transported from the stainless steel hanging cages where they were housed, placed into the white plastic cages described above, which for them was a novel environment, and immediately were given either an intraperitoneal injection of saline (novel-saline; $n=9$ ), amphetamine $(1.5 \mathrm{mg} / \mathrm{kg}$; novel-amphetamine; $n=11)$, or cocaine $(15$ $\mathrm{mg} / \mathrm{kg}$; novel-cocaine; $n=9$ ). Locomotor activity was videotaped remotely, and the number of crossovers (defined as one complete traversal of the long side of the test cage) made by the animal during the session was subsequently counted by an observer blind to the experimental group. Fifty minutes after treatment the rats were decapitated, and brains were removed and frozen in isopentane $\left(-40\right.$ to $\left.-50^{\circ} \mathrm{C}\right)$ and stored at $-80^{\circ} \mathrm{C}$. Sections $(10 \mu \mathrm{m})$ were cut at $200 \mu \mathrm{m}$ intervals through the amygdala, mounted on polylysine-coated slides, and stored at $-80^{\circ} \mathrm{C}$ until processing for in situ hybridization.

In situ hybridization for c-fos $m R N A$. The method for in situ hybridization was as previously described (Day and Akil, 1996). Briefly, a cRNA probe complementary to c-fos $(680$ mer; courtesy of Dr. T. Curran, St. Jude Children's Research Hospital, Memphis, TN) was generated and labeled with $\left[{ }^{35} \mathrm{~S}\right] \mathrm{CTP}$ and $\left[{ }^{35} \mathrm{~S}\right] \mathrm{UTP}$ (AmershamPharmaciaBiotech, Piscataway, NJ), using standard transcription methods. Brain sections were hybridized with the probe overnight, and the next day they were treated with RNase A $(200 \mu \mathrm{g} / \mathrm{ml})$ for $1 \mathrm{hr}$ at $37^{\circ} \mathrm{C}$ and washed to a final stringency of $0.1 \times \mathrm{SSC}$ at $65^{\circ} \mathrm{C}$ for $1 \mathrm{hr}$. Sections were exposed to x-ray film (Biomax-MR; Eastman Kodak, Rochester, NY) for $5 \mathrm{~d}$ before dipping in photographic emulsion (NTB2; Eastman Kodak) sections were stored in light-tight boxes for 3 weeks at $4^{\circ} \mathrm{C}$ before developing (D19; Eastman Kodak). Sections were lightly stained with cresyl violet, dehydrated, and coverslipped with a xylene-based mounting medium (Permount) for qualitative microscopic analysis.

Semiquantitative c-fos $m R N A$ analysis. Levels of c-fos mRNA were analyzed by computer-assisted optical densitometry. All sections from the BST were processed in a single in situ experiment. Similarly, all sections from the amygdala of an individual experiment were processed in a single ISH experiment. However, because the BST and amygdala sections were not processed together, and because sections from experiments 1,2 , and 3 were processed separately, they should not be compared quantitatively. Brain section images from in situ hybridization experiments were captured digitally (CCD camera, model XC-77; Sony, Tokyo, Japan), and the relative optical density of the x-ray film was determined for each brain region using NIH Image version 1.61 for Macintosh computer. A macro was written (Dr. Serge Campeau, University of Colorado) that enabled signal above background to be automatically determined. For each section, a background sample was taken over an area of white matter, and the signal threshold was calculated as mean gray value of background $+3.5 \mathrm{SD}$. The section was automatically density-sliced at this value, so that only pixels with gray values exceeding these criteria were included in the analysis. Results are expressed as mean integrated density, which reflects both the signal intensity and the number of pixels above assigned background (mean signal above background $\times$ number of pixels above background). Care was taken to ensure that equivalent areas were analyzed between animals.

Dual in situ hybridization. The method used for dual in situ hybridization has been described previously (Day et al., 1999). Briefly, cRNA probes complementary to c-fos, corticotropin-releasing hormone (CRH) (770 mer; courtesy of Dr. R. Thompson, University of Michigan), or enkephalin mRNA (693 mer; courtesy of Dr. J. Douglass, Amgen, Thousand Oaks, CA) were generated and labeled with ${ }^{35}$ S CTP and $\left[{ }^{35}\right.$ S $]$ UTP or digoxigenin-UTP (dig-UTP; Boehringer Mannheim, Indianapolis, IN) using standard transcription methods. Brain sections through the oval subnucleus of the BST (BSTov) and central nucleus of the amygdala (CEA) (from experiment 2) were hybridized overnight with either dig-c-fos and $\left[{ }^{35} \mathrm{~S}\right]$ enkephalin or dig-c-fos and $\left[{ }^{35} \mathrm{~S}\right] \mathrm{CRH}$ probes. The next day, sections were treated with RNase A $(200 \mu \mathrm{g} / \mathrm{ml})$ for $1 \mathrm{hr}$ at $37^{\circ} \mathrm{C}$ and washed to a final stringency of $0.1 \times \mathrm{SSC}$ at $65^{\circ} \mathrm{C}$ for $1 \mathrm{hr}$. Sections were then processed for visualization of the digoxigenin-labeled probe. Briefly, sections were incubated overnight with an antibody against digoxigenin and conjugated to alkaline phosphatase (sheep antidig-AP, Fab fragments; Boehringer Mannheim), diluted 1:20,000. After extensive washing, sections underwent a color reaction by addition of 
Table 1. Behavioral data for experiments 1-3

\begin{tabular}{|c|c|c|c|}
\hline & Experiment 1 & Experiment 2 & Experiment 3 \\
\hline & \# Rotations & \# Rotations & \# Crossovers \\
\hline Untreated & $11.8 \pm 2.5(4)$ & - & $7 \pm 1.9(4)$ \\
\hline Home-saline & $12.9 \pm 4.3(7)$ & - & $12.2 \pm 1.7(5)$ \\
\hline Novel-saline & $23.2 \pm 3.8(9)$ & - & $71.9 \pm 6.7(9)^{a}$ \\
\hline Home-amphetamine & $132.7 \pm 21.9(12)^{a}$ & $74.9 \pm 14(8)$ & $47.8 \pm 12.3(9)^{a}$ \\
\hline Novel-amphetamine & $178.6 \pm 20.0(11)^{b, c}$ & $119.4 \pm 6(8)^{c}$ & $96.8 \pm 7.0(9)^{b, c}$ \\
\hline Home-cocaine & - & - & $18.3 \pm 4.8(9)$ \\
\hline Novel-cocaine & - & - & $101.4 \pm 12.1(9)^{b, d}$ \\
\hline
\end{tabular}

Experiment 1 and 2, Total number of rotations exhibited by 6-OHDA-lesioned rats in the 50 min after amphetamine (2 $\mathrm{mg} / \mathrm{kg}$, i.p.) or saline injection in a home or novel environment. Experiment 3, Total number of crossovers in the $50 \mathrm{~min}$ after amphetamine (1.5 mg/kg, i.p.), cocaine $(15 \mathrm{mg} / \mathrm{kg}$, i.p.), or saline injection in a home or novel environment. Data from two animals in the novel-amphetamine group are missing because of videotaping failure. Number per group is indicated in parentheses.

${ }^{a} p<0.01$ with respect to home-saline group.

${ }^{b} p<0.05$ with respect to novel-saline group.

${ }^{c} p<0.05$ with respect to home-amphetamine group.

${ }^{d} p<0.01$ with respect to home-cocaine group.

$0.45 \%$ nitro blue tetrazolium chloride (Boehringer Mannheim) and 0.35\% 5-bromo-4-chloro-3-indoylphosphate 4-toluidine salt (Boehringer Mannheim). After completion of the color reaction $(\sim 18 \mathrm{hr})$, sections were rinsed and stripped of antibody by incubating with $0.1 \mathrm{M}$ glycine and $0.5 \%$ Triton X-100, pH 2.2, for 10 min. Finally, sections were fixed in $2.5 \%$ glutaraldehyde for $1 \mathrm{hr}$. These last steps were found to help prevent the increase in background after processing for radioactive signal. After exposure to $\mathrm{x}$-ray film ( $1 \mathrm{~d}$ for $\left[{ }^{35} \mathrm{~S}\right]$ enkephalin and $5 \mathrm{~d}$ for $\left.\left[{ }^{35} \mathrm{~S}\right] \mathrm{CRH}\right)$, sections were dipped in liquid emulsion (Ilford KD-5; Polysciences, Warrington, PA) and stored in light-tight boxes at $4{ }^{\circ} \mathrm{C}$ for $3 \mathrm{~d}\left(\left[{ }^{35} \mathrm{~S}\right] \mathrm{en}-\right.$ kephalin) or 1 month $\left(\left[{ }^{35} \mathrm{~S}\right] \mathrm{CRH}\right)$. After this time sections were developed (Kodak D-19), dehydrated, and coverslipped in a xylene-based mounting medium (Permount; Fisher Scientific, Houston, TX). The cellular distribution was determined using a Leica (Nussloch, Germany; Leitz DMR) microscope. The nonradioactive probe was visualized under bright field as a blue-purple precipitate, whereas the radioactive probe was visualized under dark field by silver grain distribution. Sections through the BSTov and CEA were analyzed to determine the extent of colocalization. Cells were counted with the aid of an eyepiece grid. For each animal, between two and four sections for the BSTov and four to eight sections for the CEA were analyzed bilaterally. At least five animals per group were analyzed for each probe combination. No attempt was made to determine absolute cell counts. Rather, we aimed to analyze an adequate number of cells to estimate the percentage of double-labeled neurons.

Statistical analysis. Rotational data were analyzed by one-way ANOVA (experiment 1: group, 5 levels; experiment 2: group, 2 levels), followed by Fisher's protected least significant difference (PLSD) tests. For crossover data (experiment 3), because they were not statistically different, untreated and home-saline groups were pooled, and data were analyzed by two-way ANOVA (environment and drug treatment) followed by Fisher's PLSD tests. Group differences in c-fos mRNA levels from experiment 1 were analyzed by three-way ANOVA, including lesion type (lesion or intact), environment (home or novel), and injection (saline or amphetamine). Because there were interaction effects between environment and injection, but no effects of lesion on c-fos mRNA expression, the data from the lesion and intact conditions were pooled. These data, and those from experiments 2 and 3, were analyzed by a one-way ANOVA (group, two, five, or seven levels as appropriate for brain area and experiment) followed by Fisher's PLSD tests.

\section{RESULTS}

\section{Experiment 1}

\section{Behavior}

Consistent with previous observations, untreated or salinetreated animals in either home or novel context showed no significant rotational behavior. Animals treated with amphetamine ( $2 \mathrm{mg} / \mathrm{kg}$, i.p.) in the home environment demonstrated a significant increase in rotational behavior, which was further increased in animals treated with the same dose of amphetamine in a novel environment (Table 1).

\section{$c$-fos $m R N A$ expression}

For all regions, the levels of c-fos mRNA were quantified separately for the lesioned and intact sides, but there was no effect of the lesion in any of the groups, in any of the regions studied. Hence, data are shown as the mean of lesion and intact sides for each animal. Environmental novelty and amphetamine administration, alone or in combination, had differential effects on the patterns of c-fos mRNA expression in different subnuclei of the BST and amygdala.

The medial nucleus of the amygdala (MEA) and medial posterior nucleus of the BST (BSTmp) have been associated under the extended amygdala concept, as proposed by Alheid and Heimer (1988). In these regions, untreated animals and those injected with either saline or amphetamine in the home environment expressed very low levels of c-fos mRNA, with no significant differences between groups (Fig. $1 A, B$ ). Exposure to novelty, whether associated with a saline injection $(p<0.0001$ vs homesaline group for both MEA and BSTmp) or amphetamine injection $(p<0.0001$ vs home-amphetamine group for both MEA and BSTmp), increased the levels of c-fos mRNA to a similar extent.

In the basolateral (BLA) and lateral (LA) nuclei of the amygdala, untreated and home-saline animals expressed very little c-fos mRNA, with no significant difference between the groups (Fig. 1C). Mere exposure to novelty (in the absence of amphetamine) increased the levels of c-fos mRNA in these regions $(p<$ 0.01 vs home-saline group). Amphetamine administration in the home environment also increased the levels of c-fos mRNA ( $p<$ 0.05 vs home-saline group), to a similar extent as observed with novelty alone. The combination of novelty plus amphetamine increased the levels of c-fos mRNA further $(p<0.0001$ vs home-saline group; $p<0.001$ vs novel-saline group; $p<0.0001$ vs home-amphetamine group), to a level that was approximately additive with respect to novel-saline and home-amphetamine groups. Unfortunately we were unable to analyze c-fos mRNA expression in individual nuclei because sections were taken at relatively rostral levels, so that the level of the lateral nucleus in particular was fairly anterior. However, it appeared that c-fos 

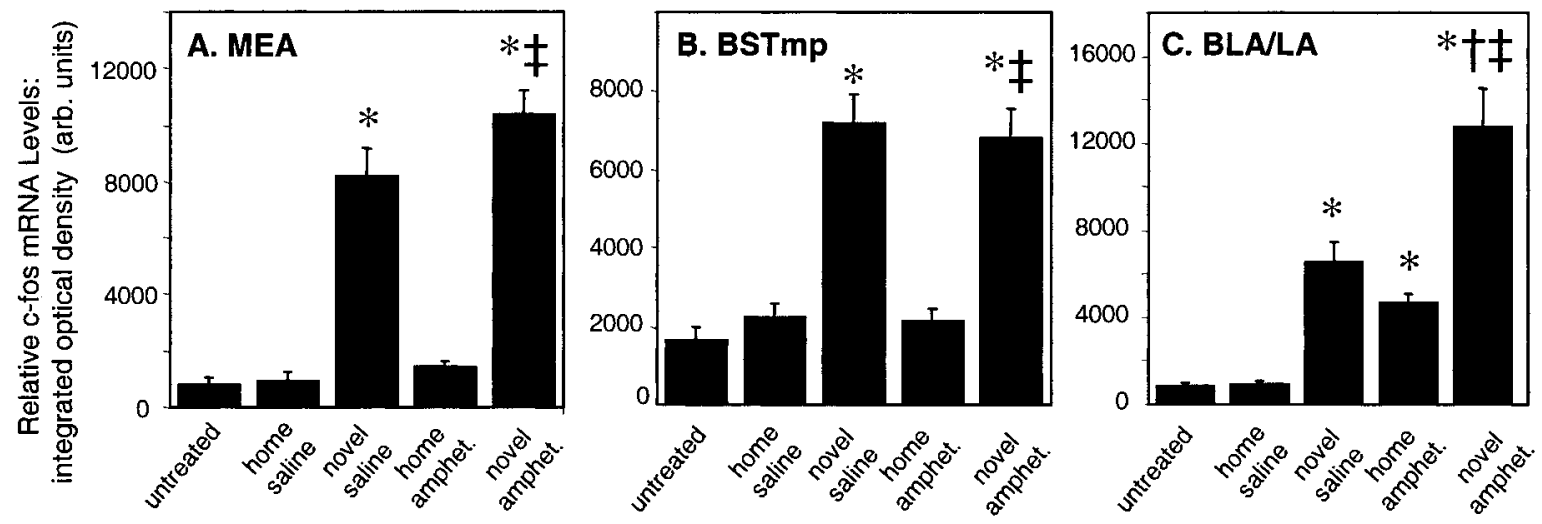

Figure 1. Expression of c-fos mRNA in MEA $(A)$, BSTmp $(B)$, and BLA and LA $(C)$ of 6-OHDA-lesioned rats $50 \mathrm{~min}$ after amphetamine $(2 \mathrm{mg} / \mathrm{kg}$, i.p.) or saline administration in a home or novel environment (experiment 1). Values represent the mean integrated density (see Materials and Methods for definition) \pm SEM. ${ }^{*} p<0.05$ with respect to home-saline group; $\downarrow p<0.001$ with respect to novel-saline group; $\ddagger p<0.001$ with respect to home-amphetamine group.

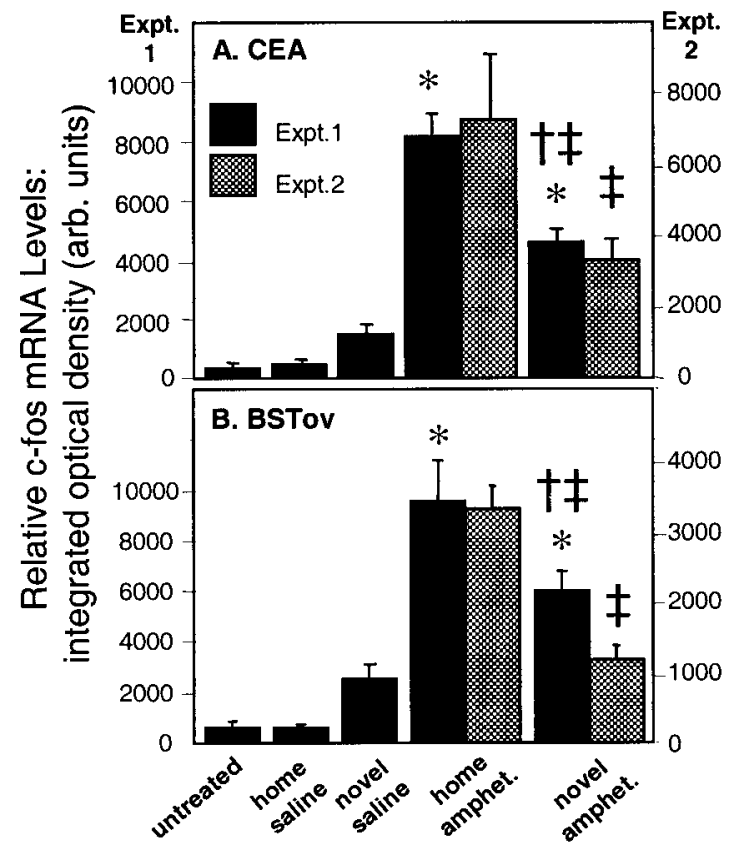

Figure 2. Expression of c-fos mRNA in CEA $(A)$ and BSTov $(B)$ of 6-OHDA lesioned rats $50 \mathrm{~min}$ after amphetamine $(2 \mathrm{mg} / \mathrm{kg}$, i.p. $)$ or saline administration in a home or novel environment (experiments 1 and 2). Note that in experiment 2, only home-amphetamine and novelamphetamine groups were run. Values represent the mean integrated density (see Materials and Methods for definition) \pm SEM. ${ }^{*} p<0.001$ with respect to home-saline group; $\dagger p<0.01$ with respect to novel-saline group; $\ddagger p<0.01$ with respect to home-amphetamine group.

mRNA expression was greater in the medial aspect of each nucleus.

A most unusual pattern of c-fos mRNA expression was observed in the CEA (Figs. 2A, 3) and BSTov (Figs. 2B, 4). These nuclei have been associated anatomically within the central extended amygdala. In these regions, expression of c-fos mRNA was extremely low in the untreated and home-saline groups, with no significant difference between groups. Exposure to novelty alone resulted in a trend toward greater expression of c-fos mRNA in both the CEA and BSTov, but these effects were not statistically significant. Amphetamine administered in the home environment resulted in a robust increase in c-fos mRNA levels in both nuclei
( $p<0.0001$ vs home-saline group for both BSTov and CEA). In contrast to the usual additive effect of novelty and amphetamine on c-fos mRNA observed in most other brain regions (Badiani et al., 1998), amphetamine administered in the novel environment resulted in a smaller induction of c-fos mRNA expression in the BSTov and CEA, as compared with the home-amphetamine group (BSTov, $p<0.01$ vs novel-saline and home-amphetamine groups; CEA, $p<0.001$ vs novel-saline group; $p<0.0001$ vs home-amphetamine group). In both home- and novelamphetamine groups, expression within the CEA was essentially confined to the lateral division (CEAl), and was highest ventrally toward the caudal extent of the nucleus.

\section{Experiment 2}

Animals receiving amphetamine in the novel environment exhibited significantly greater rotational behavior than those receiving amphetamine at home (Table 1). As was observed in experiment 1, c-fos mRNA expression in the CEA (Fig. $2 A$ ) and BSTov (Fig. $2 B$ ) was significantly greater in animals that had received amphetamine in the home environment, compared with those experiencing amphetamine in a novel environment.

Previous studies have shown the existence of two distinct populations of cells within the BSTov and CEAl (Day et al., 1999). One population expresses CRH mRNA and another enkephalin mRNA, with very little overlap between these two cell populations. In the current study, dual in situ hybridization experiments revealed that within the BSTov and CEAl, amphetamine-induced c-fos mRNA expression was rarely colocalized with CRH mRNA (Table 2, Fig. $5 A$ ), with $<2 \%$ of c-fos mRNA-positive cells expressing CRH mRNA in either brain region. In contrast, the majority of cells expressing c-fos mRNA also expressed enkephalin mRNA (Table 2, Fig. 5B). The percentage of c-fos mRNA-expressing cells that expressed enkephalin mRNA varied from $\sim 80-85 \%$ for the BSTov to $90 \%$ for the CEAl. This pattern of expression was independent of the environmental context in which the amphetamine was administered, with a similar proportion of double-labeled cells observed for each group.

\section{Experiment 3}

\section{Behavior}

In neurologically intact rats, locomotor activity was very low, as measured by the number of crossovers during the session, in 

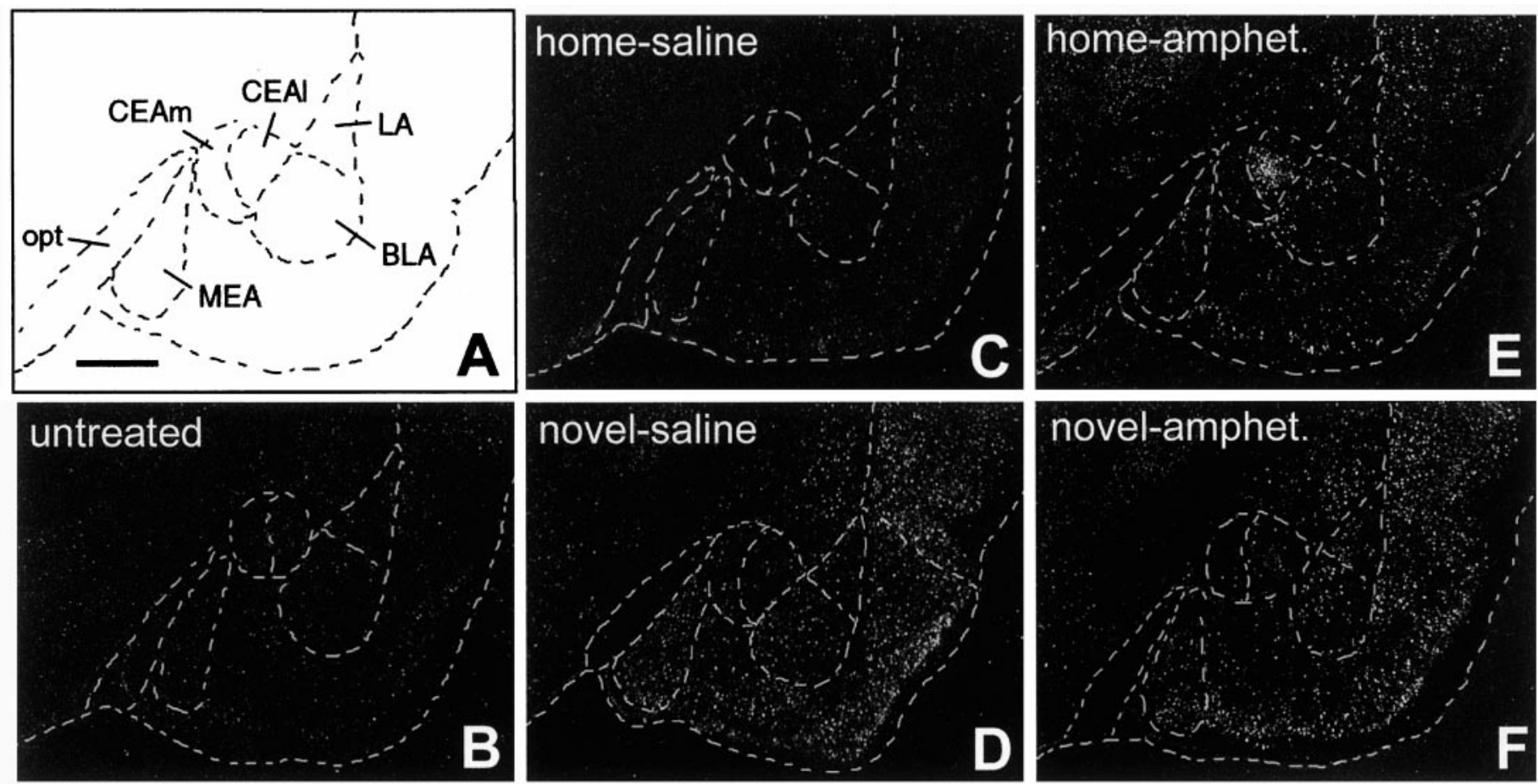

Figure 3. Schematic diagram $(A)$ and photomicrographs $(B-F)$ showing c-fos mRNA expression in the CEA, 50 min after amphetamine (amphet; 2 $\mathrm{mg} / \mathrm{kg}$, i.p.; $E, F)$ or saline $(C, D)$ administration in a home $(B, C, E)$ or novel $(D, F)$ environment (experiment 1$)$. opt, Optic tract. Scale bar, 1 mm.
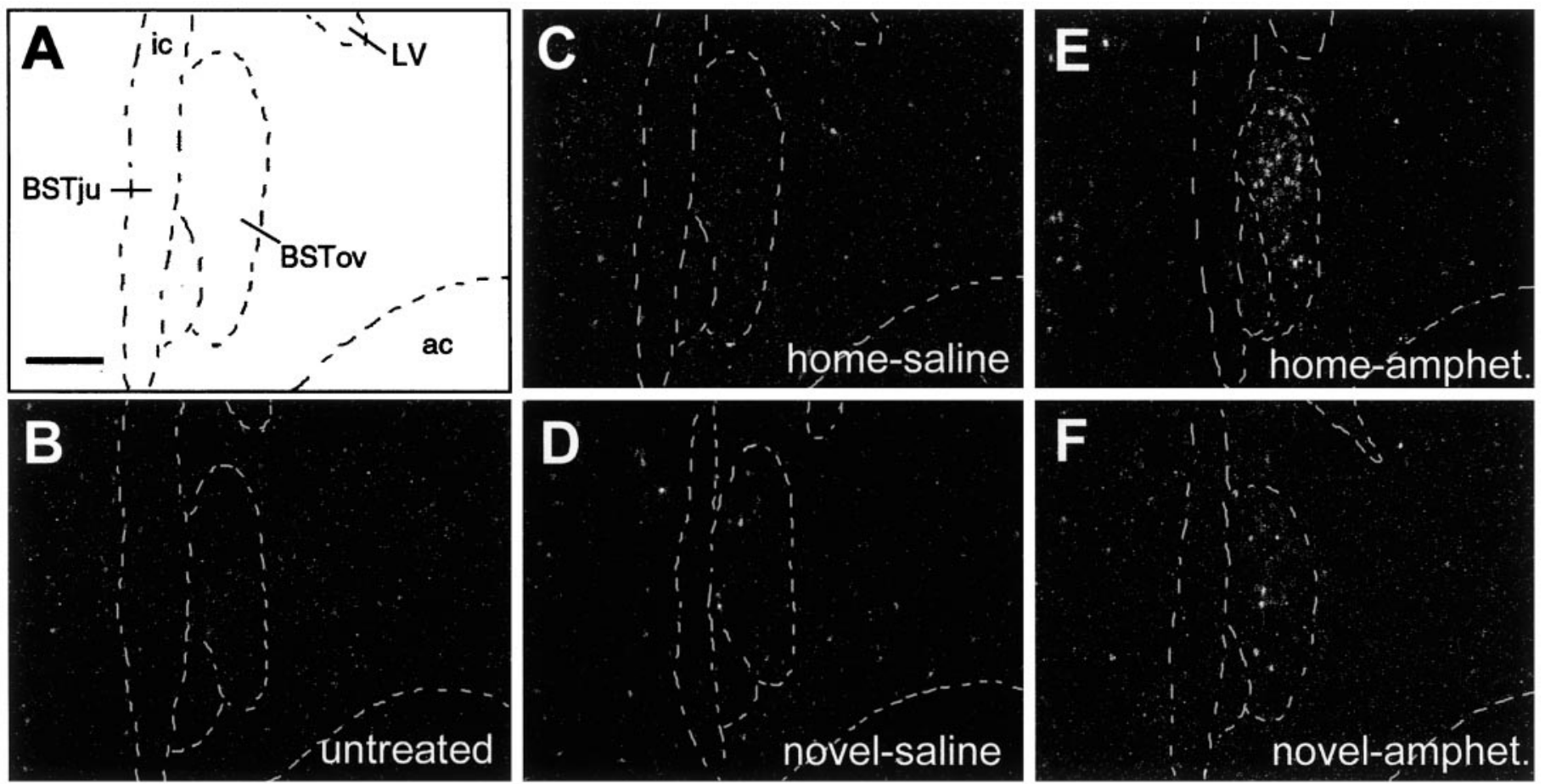

Figure 4. Schematic diagram $(A)$ and photomicrographs $(B-F)$ showing c-fos mRNA expression in the BSTov, 50 min after amphetamine (amphet; 2 $\mathrm{mg} / \mathrm{kg}$, i.p.; $E, F)$ or saline $(C, D)$ administration in a home $(B, C, E)$ or novel $(D, F)$ environment (experiment 1$)$. $a c$, Anterior commissure; $B S T j u$, juxtacapsular nucleus of the BST; $i c$, internal capsule; $L V$, lateral ventricle. Scale bar, $300 \mu \mathrm{m}$.

animals that were untreated or received saline at home (Table 1). In contrast to rotational behavior observed in experiment 1 , animals that received a saline injection in the novel environment exhibited significantly higher locomotor activity as compared with the home-saline group $(p<0.0001)$. Amphetamine administered in the home environment also resulted in significantly elevated locomotor activity, compared with home-saline animals. When amphetamine was administered in the novel environment, locomotor activity was further enhanced $(p<0.05$ compared with novel-saline group; $p<0.01$ compared with home-amphetamine 
Table 2. Colocalization of $c$-fos mRNA in CRH or enkephalin mRNA containing cells of the BSTov or CEA (experiment 2)

\# of single-labeled $c$-fos \# of double-labeled $c$-fos

cells counted cells counted

$\%$ c-fos cells colocalized

with $\mathrm{CRH}$

\begin{tabular}{|c|c|c|c|c|}
\hline \multicolumn{5}{|l|}{ BSTov } \\
\hline Home & $0.9 \pm 0.6$ & $26.6 \pm 4.3$ & $0.3 \pm 0.2$ & 8 \\
\hline \multicolumn{5}{|c|}{$\begin{array}{c}\% c \text {-fos cells colocalized } \\
\text { with ENK }\end{array}$} \\
\hline Home & $79.4 \pm 1.3$ & $9.3 \pm 1.7$ & $35.3 \pm 5.9$ & 8 \\
\hline \multicolumn{5}{|c|}{$\begin{array}{c}\% c-f o s \text { cells colocalized } \\
\text { with } \mathrm{CRH}\end{array}$} \\
\hline \multicolumn{5}{|l|}{ CEA } \\
\hline Home & $0.4 \pm 0.3$ & $72.2 \pm 10.2$ & $0.3 \pm 0.2$ & 6 \\
\hline Novel & $\begin{array}{l}0.4 \pm 0.4 \\
\% \text { c-fos cells colocalized } \\
\quad \text { with ENK }\end{array}$ & $54.8 \pm 4.4$ & $0.2 \pm 0.2$ & 5 \\
\hline Home & $91.2 \pm 0.7$ & $7.1 \pm 2.4$ & $69.6 \pm 17.1$ & 8 \\
\hline Novel & $90.4 \pm 2.7$ & $4.4 \pm 1.8$ & $37.4 \pm 7.9$ & 7 \\
\hline
\end{tabular}

For $c$-fos mRNA colocalization with CRH mRNA, results are expressed for the intact side alone, because CRH mRNA was significantly decreased in these regions on the lesioned side. For $c$-fos mRNA colocalization with enkephalin mRNA, results are expressed for intact and lesioned sides combined because there were no statistically significant differences between the two sides. All data are expressed as mean \pm SEM. It should be noted that the numbers of cells counted do not reflect absolute numbers of cells expressing $c$-fos mRNA per animal. Rather, a sample of the cells in each area was counted to estimate the relative proportion of single- versus double-labeled cells.
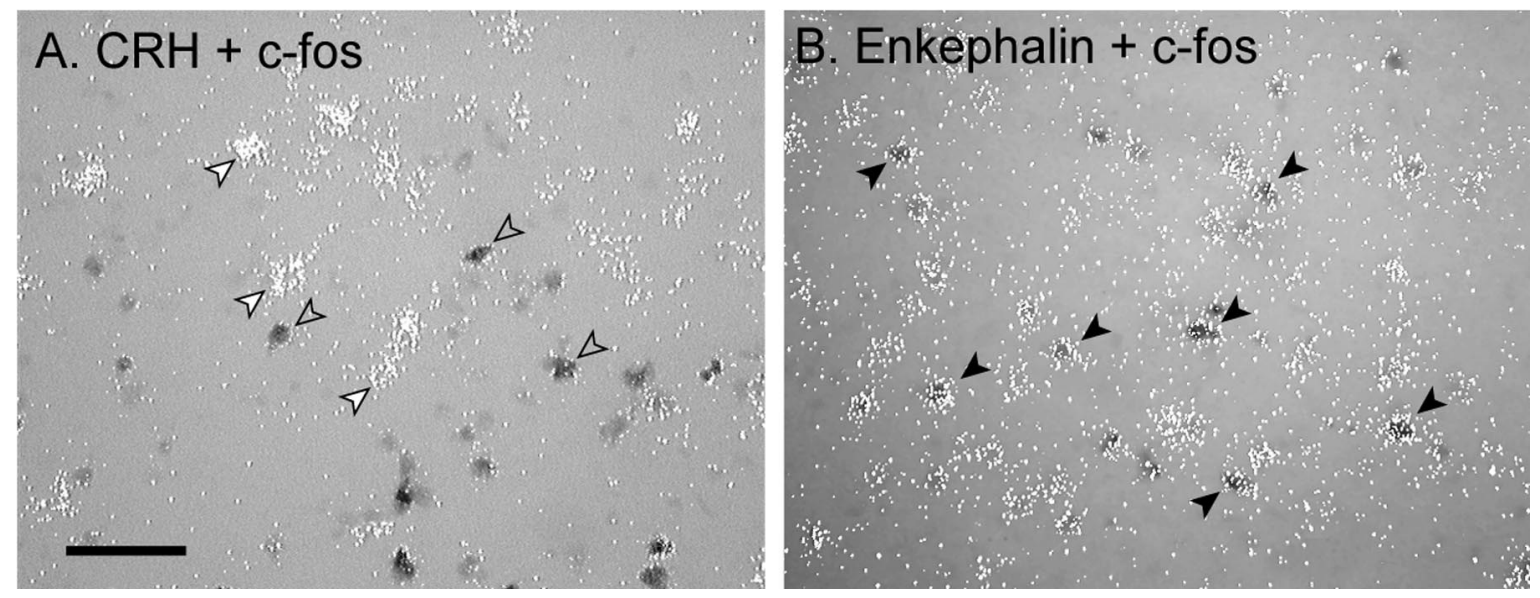

Figure 5. Photomicrographs showing dual in situ hybridization of c-fos mRNA (digoxigenin-labeled probe, dark gray cells) with CRH ( $A$ ) or enkephalin $(B)$ mRNA $\left({ }^{35} \mathrm{~S}\right.$-labeled probe, clusters of white grains) in the central nucleus of the amygdala, $50 \mathrm{~min}$ after amphetamine administration (2 mg/kg, i.p.) in a home environment. Open arrows, Cells labeled for c-fos mRNA only; white arrows, cells labeled for CRH mRNA only; black arrows, cells labeled for c-fos and enkephalin mRNA. Scale bar, $50 \mu \mathrm{m}$.

group.) Cocaine administered in the home environment did not alter locomotor activity, but when administered in the novel environment, locomotor activity was significantly increased $(p<$ 0.05 compared with novel-saline group; $p<0.01$ compared with home-cocaine group.)

\section{$c$-fos $m R N A$ expression}

In the MEA of neurologically intact rats, amphetamine administration in the home versus novel environment resulted in a very similar pattern of c-fos mRNA expression to that observed in
6-OHDA-lesioned animals (Fig. 6A). That is, exposure to novelty, whether associated with a saline injection or amphetamine injection, increased the levels of c-fos mRNA to a similar extent. Furthermore, cocaine administration in a home versus novel environment resulted in an almost identical pattern of c-fos mRNA expression (Table 3 ). Animals receiving cocaine in the home environment exhibited very little c-fos mRNA in this region, and those receiving cocaine in the novel environment expressed c-fos mRNA to a similar extent to the novel-saline group. In the BLA and LA, the pattern of amphetamine-induced c-fos 

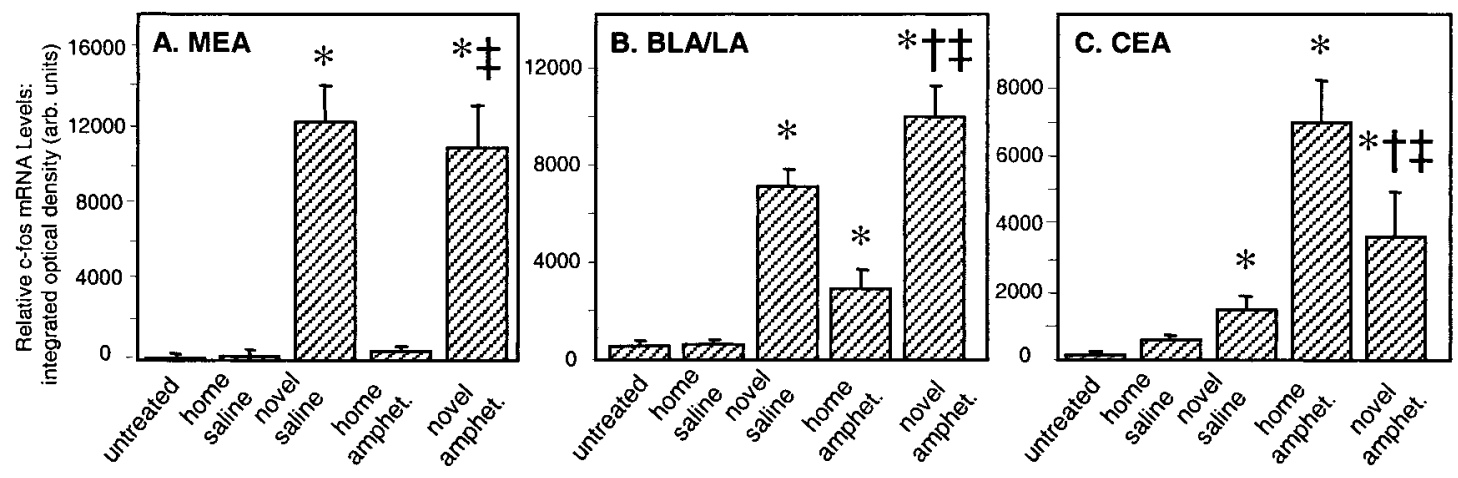

Figure 6. Expression of c-fos mRNA in MEA $(A)$, BLA and LA $(B)$, and CEA $(C)$ of neurologically intact rats 50 min after amphetamine $(1.5 \mathrm{mg} / \mathrm{kg}$, i.p.) or saline administration in a home or novel environment (experiment 3). Values represent the mean integrated density (see Materials and Methods for definition) \pm SEM. ${ }^{*} p<0.05$ with respect to home-saline group; $t p<0.05$ with respect to novel-saline group; $\ddagger p<0.05$ with respect to home-amphetamine group.

Table 3. Relative $c$-fos mRNA levels (integrated optical density: arbitrary units) in neurologically intact rats, after cocaine $(15 \mathrm{mg} / \mathrm{kg}$, i.p.) or saline administration in a home or novel environment (experiment 3)

\begin{tabular}{lccc} 
& MEA & BLA $/$ LA & CEA \\
\hline Untreated $(n=4)$ & $177 \pm 37$ & $530 \pm 179$ & $190 \pm 60$ \\
Home-saline $(n=5)$ & $291 \pm 77$ & $648 \pm 187$ & $552 \pm 213$ \\
Novel-saline $(n=9)$ & $12311 \pm 1856^{a}$ & $7083 \pm 721^{a}$ & $1483 \pm 366^{a}$ \\
Home-cocaine $(n=9)$ & $1044 \pm 453$ & $3444 \pm 801^{a}$ & $4236 \pm 1095^{a}$ \\
Novel-cocaine $(n=9)$ & $12070 \pm 2738^{b}$ & $9803 \pm 2818^{b}$ & $3357 \pm 660^{c}$
\end{tabular}

${ }^{a} p<0.05$ compared to home-saline group.

${ }^{b} p<0.05$ compared with home-cocaine group.

${ }^{c} p<0.05$ compared with novel-saline group.

mRNA expression in intact animals was broadly similar to that observed previously in unilateral 6-OHDA-lesioned animals (Fig. $6 B$ ). Both exposure to novelty and amphetamine at home resulted in significant c-fos mRNA expression. Amphetamine given in combination with novelty resulted in enhanced c-fos mRNA expression, so that the levels were essentially additive. However, in neurologically intact rats, c-fos mRNA levels in the novel-saline group were significantly higher than in the home-amphetamine group, whereas in rats with a 6-OHDA lesion, these two groups showed a similar c-fos mRNA response. This may be related to the greater behavioral response to a novel environment in intact versus 6-OHDA-lesioned animals (Table 1). The pattern of expression observed after cocaine treatment was very similar to that seen with amphetamine (Table 3 ).

In the CEA, the pattern of amphetamine-induced c-fos mRNA expression in intact animals again was broadly similar to that observed in rats with a unilateral 6-OHDA lesion (Fig. 6C). Novelty alone elicited a small, but significant increase in c-fos mRNA $(p<0.05$ compared with home-saline and untreated animals), whereas amphetamine at home elicited a robust response ( $p<0.0001$ compared with home-saline group). When given in association with a novel environment, amphetamine elicited a relatively smaller c-fos mRNA response $(\sim 50 \%)$, as compared with the home-amphetamine group $(p<0.05)$. Animals treated with cocaine in the home environment also expressed robust levels of c-fos mRNA (Table 3). Although there was a trend toward decreased c-fos mRNA expression when cocaine was administered in association with novelty, the effect was not statistically significant.

\section{DISCUSSION}

This study presents further evidence supporting the idea that the neural circuitry engaged by amphetamine or cocaine is not a simple function of their direct pharmacological actions, but rather is dependent on the context in which they are experienced. In most brain regions environmental novelty potentiates amphetamine-induced c-fos mRNA expression (Badiani et al., 1998, 1999), but here we report that in the CEA novelty inhibits amphetamine-induced c-fos mRNA expression. These data suggest that patterns of psychostimulant drug-induced gene expression in widespread neural circuits are modulated in complex ways by the context in which drugs are experienced. This may be related to the ability of environmental context to modulate both acute drug responsiveness and their ability to promote neurobehavioral plasticity.

\section{MEA and BSTmp}

The pattern of c-fos mRNA expression observed in the MEA and BSTmp was similar to that observed previously in the neocortex and septum (Badiani et al., 1998). Exposure to novelty increased c-fos mRNA expression, which was not augmented by amphetamine administration. This may be because exposure to novelty is stressful, as indicated by increased plasma corticosterone (Badiani et al., 1998, their Fig. 13). Indeed, other "processive" stressors (defined as stressors requiring interpretation by higher brain structures; Herman and Cullinan, 1997) increase c-fos mRNA levels in the MEA and medial BST (Cullinan et al., 1995; Kollack-Walker et al., 1997). Given the lack of induction of c-fos mRNA by amphetamine at home or potentiation of noveltyinduced c-fos mRNA, it appears that the MEA and BSTmp are not involved in the response to amphetamine per se. This is despite the fact that administration of amphetamine is stressful, as determined by elevated plasma corticosterone (Badiani et al., 1998, their Fig. 13), suggesting that these regions may respond selectively to processive rather than "systemic" stressors. Furthermore, the lack of cocaine-induced c-fos mRNA in the MEA suggests that this region is more likely to be involved in stress responsiveness than in the response to psychostimulants. It seems likely that the c-fos mRNA expression elicited by the combination of amphetamine or cocaine and novelty was attributable entirely to the novelty component, but we cannot exclude the possibility that different neuronal populations were activated under these conditions. 


\section{BLA and LA}

In the BLA and LA, novelty alone or amphetamine or cocaine at home increased c-fos mRNA expression. When amphetamine or cocaine was given in association with novelty, c-fos mRNA expression was further enhanced. This pattern has been observed in other brain regions, including the $\mathrm{CP}$ and $\mathrm{ACB}$ core (Badiani et al., 1998). The LA receives significant sensory input (Doron and LeDoux, 1999) and the relatively high c-fos mRNA response to novelty in intact versus lesioned animals may reflect an increase in sensory input resulting from increased exploration of the cage. The LA projects heavily to the majority of other amygdaloid nuclei including the BLA (Pitkanen et al., 1995), which has been implicated in the response to affective stimuli and in the process of conditioned reinforcement (Everitt et al., 1999). Furthermore, the BLA has a substantial projection to the ACB shell (Alheid and Heimer, 1988), an area thought to be integral in the reinforcing actions of drugs of abuse.

There is considerable evidence that DA plays a significant role in modulating BLA activity. For example, DA levels are increased in the BLA during learning (Hori et al., 1993) and in response to stressful stimuli (Herman et al., 1982) or to stimuli predictive of food reward (Harmer and Phillips, 1999). Furthermore, DA modulates neuronal firing and afferent drive of the BLA and has been suggested to augment the response to affective sensory stimuli (Rosenkranz and Grace, 1999). Although the present data do not indicate whether DA is involved in the observed c-fos mRNA response, the DA-releasing properties of amphetamine and cocaine and the stressful nature of the novel environment are consistent with the possibility of DA involvement (but see discussion below). The present data suggest that quantitatively, the effects of novelty and amphetamine or cocaine on c-fos mRNA in the BLA and LA are additive. This raises the possibility that the BLA is important in processing the complex interactions between the effects of drugs of abuse and environmental context. However, the data do not indicate whether the same cell populations are engaged by amphetamine or cocaine and environmental novelty. Indeed, we have recently shown that in the CP, amphetamine induces c-fos mRNA expression in cells positive for D2 DA receptor mRNA when given in a novel environment, but not when given at home (Badiani et al., 1999), indicating that different neural circuitry is involved in the response to amphetamine in different environmental contexts.

\section{CEA and BSTov}

In the CEA and BSTov, amphetamine at home induced robust c-fos mRNA expression, but significantly lower expression, when given in a novel environment. This pattern is highly unusual, differing fundamentally from the patterns found in every other brain region we have studied to date (Badiani et al., 1998, 1999). Although a trend toward this pattern was seen in cocaine-treated animals, the difference was not statistically significant. This may be because the dose of cocaine used was not optimal, or this pattern of expression could be specific for amphetamine. The CEA and BSTov are involved in the central regulation of autonomic functions, including cardiovascular activity (Saper, 1995). Acute amphetamine increases both blood pressure and heart rate via peripheral mechanisms, and the CNS is thought to inhibit this effect (Simpson, 1975, 1976). It is conceivable that the BSTov and CEA c-fos mRNA response to amphetamine at home reflects this inhibitory output. For animals exposed to novelty, the increase in heart rate and blood pressure is thought to result from processing of information at a central rather than peripheral level (Mori- moto et al., 1993), and we speculate that the BSTov and CEAl may be involved in this regulation. Thus, when amphetamine is administered in a novel environment, there is a smaller c-fos mRNA response, perhaps via active inhibition of these structures. To our knowledge, the cardiovascular response to amphetamine administration in a home versus novel environment has not been studied, and would be of interest to investigate. In addition, the CEA may play a role in the reinforcing actions of drugs of abuse (Koob, 1999). Although this study does not address the issue of reinforcement, the ability of novelty to inhibit amphetamineinduced c-fos mRNA in the CEA may have important implications for both an animal's acute and subsequent responses to the drug.

It is not clear which neuronal circuits are involved in the CEA or BSTov c-fos mRNA responses to amphetamine in different environmental contexts. We have previously demonstrated the existence of two GABAergic neuronal populations in the BSTov and CEA, containing either enkephalin or CRH mRNA (Day et al., 1999). Amphetamine-induced c-fos mRNA was highly colocalized with enkephalin, but rarely with CRH mRNA, regardless of environmental condition. This does not imply that identical neuronal pathways were involved in the response. It is possible that novelty inhibits the amphetamine-stimulated neurons that are responsible for induction of c-fos mRNA in the BSTov and CEA. Alternatively, novelty may activate a different inhibitory pathway that synapses on the same cells of the BSTov and CEA. Furthermore, it must be recognized that the lack of c-fos mRNA expression in CRH-positive cells does not indicate a lack of involvement. Indeed, it has recently been shown that there are substantial intranuclear connections within the lateral division of the CEA (Petrovich and Swanson, 1997; Jolkkonen and Pitkanen, 1998), raising the intriguing possibility that enkephalincontaining cells actively inhibit the CRH-containing cells.

\section{Dopaminergic involvement}

The extent of dopaminergic involvement in the BST and amygdala c-fos mRNA response to amphetamine in different environments remains to be determined. Dopaminergic input is certainly rich to these areas (Freedman and Cassell, 1994; Asan, 1998). The extent of DA depletion in the amygdala or BST of animals sustaining a 6-OHDA lesion of the medial forebrain bundle is unclear. The lack of effect of the lesion on amphetamine-induced c-fos mRNA in any of the regions examined suggests that either the DA input to these areas was not depleted sufficiently or that DA is not necessary for the c-fos mRNA response to amphetamine. Interestingly, the 6-OHDA lesion did have some effect in these regions. In the same animals we observed that $\mathrm{CRH}$ and neurotensin mRNAs were significantly decreased in the BSTov and CEA on the lesioned side (Day et al., 2000). Conversely, the c-fos mRNA response to amphetamine is not restricted to animals with a 6-OHDA lesion, because a similar pattern of expression was observed in the amygdala of neurologically intact rats.

In conclusion, the differential effects of exposure to a novel environment on amphetamine-induced c-fos mRNA expression in the BST and amygdala lends support to the idea that the neurocircuitry engaged by amphetamine is not only dependent on its pharmacological properties, but also on the context in which it is experienced. The response in these areas is of particular interest given the potential role that they play in emotional and associative processes involved in the reinforcing effects of amphetamine. Taken together with data from previous studies (Badiani et al., 1998, 1999), the differential effects of environmental 
context on the magnitude of response and neurons recruited strongly suggest that an animal's response to amphetamine is not simply quantitatively different under the two conditions. Rather, we suggest that the context in which amphetamine is administered qualitatively alters its neurobiological effects, and therefore the drug experience.

\section{REFERENCES}

Alheid GF, Heimer L (1988) New perspectives in basal forebrain organization of special relevance for neuropsychiatric disorders: the striatopallidal, amygdaloid, and corticopetal components of substantia innominata. Neuroscience 27:1-39.

Asan E (1998) The catecholaminergic innervation of the rat amygdala. Adv Anat Embryol Cell Biol 142:1-118.

Badiani A, Anagnostaras SG, Robinson TE (1995a) The development of sensitization to the psychomotor stimulant effects of amphetamine is enhanced in a novel environment. Psychopharmacology (Berl) 117:443-452.

Badiani A, Browman KE, Robinson TE (1995b) Influence of novel versus home environments on sensitization to the psychomotor stimulant effects of cocaine and amphetamine. Brain Res 674:291-298.

Badiani A, Camp DM, Robinson TE (1997) Enduring enhancement of amphetamine sensitization by drug-associated environmental stimuli. J Pharmacol Exp Ther 282:787-794.

Badiani A, Oates MM, Day HE, Watson SJ, Akil H, Robinson TE (1998) Amphetamine-induced behavior, dopamine release, and c-fos mRNA expression: modulation by environmental novelty. J Neurosci 18:10579-10593.

Badiani A, Oates MM, Day HE, Watson SJ, Akil H, Robinson TE (1999) Environmental modulation of amphetamine-induced c-fos expression in D1 versus D2 striatal neurons. Behav Brain Res 103:203-209.

Badiani A, Oates MM, Fraioli S, Browman KE, Ostrander MM, Xue CJ, Wolf ME, Robinson TE (2000) Environmental modulation of the response to amphetamine: dissociation between effects on behavior and on the release of dopamine and glutamate in the striatal complex. Psychopharmacology 151:166-174.

Crombag HS, Badiani A, Robinson TE (1996) Signalled versus unsignalled intravenous amphetamine: large differences in the acute psychomotor response and sensitization. Brain Res 722:227-231.

Cullinan WE, Herman JP, Battaglia DF, Akil H, Watson SJ (1995) Pattern and time course of immediate early gene expression in rat brain following acute stress. Neuroscience 64:477-505.

Day HE, Akil H (1996) Differential pattern of c-fos mRNA in rat brain following central and systemic administration of interleukin-1-beta: implications for mechanism of action. Neuroendocrinology 63:207-218.

Day HE, Curran EJ, Watson Jr SJ, Akil H (1999) Distinct neurochemical populations in the rat central nucleus of the amygdala and bed nucleus of the stria terminalis: evidence for their selective activation by interleukin-1beta. J Comp Neurol 413:113-128.

Day HEW, Badiani A, MM Oates MM, Vittoz NM, Robinson TE, Watson SJ, Akil H (2000) Expression of $\mathrm{CRH}$ and neurotensin mRNA in the amygdala and BST is decreased by a 6-hydroxydopamine lesion of the mesostriatal dopamine system. Society for Neuroscience Annual Meeting, New Orleans.

Doron NN, LeDoux JE (1999) Organization of projections from the lateral amygdala from the auditory and visual areas of the thalamus in the rat. J Comp Neurol 412:383-409.

Emmert MH, Herman JP (1999) Differential forebrain c-fos mRNA induction by ether inhalation and novelty: evidence for distinctive stress pathways [In Process Citation]. Brain Res 845:60-67.
Engber TM, Koury EJ, Dennis SA, Miller MS, Contreras PC, Bhat RV (1998) Differential patterns of regional c-fos induction in the rat brain by amphetamine and the novel wakefulness-promoting agent modafinil. Neurosci Lett 241:95-98.

Everitt BJ, Parkinson JA, Olmstead MC, Arroyo M, Robledo P, Robbins TW (1999) Associative processes in addiction and reward. The role of amygdala-ventral striatal subsystems. Ann NY Acad Sci 877:412-438.

Falk J, Feingold D (1987) Environmental and cultural factors in the behavioral actions of drugs. In: Psychopharmacology: the third generation of progress (Meltzer H, ed), pp 1503-1510. New York: Raven.

Freedman LJ, Cassell MD (1994) Distribution of dopaminergic fibers in the central division of the extended amygdala of the rat. Brain Res 633:243-252.

Harmer C, Phillips G (1999) Enhanced dopamine efflux in the amygdala by a predictive, but not a non-predictive, stimulus: facilitation by prior repeated D-amphetamine. Neuroscience 90:119-130.

Herman J, Cullinan W (1997) Neurocircuitry of stress: central control of the hypothalamic-pituitary-adrenocortical axis. Trends Neurosci 20:78-84.

Herman JP, Guillonneau D, Dantzer R, Scatton B, Semerdjian-Rouquier L, Le Moal M (1982) Differential effects of inescapable footshocks and of stimuli previously paired with inescapable footshocks on dopamine turnover in cortical and limbic areas of the rat brain. Life Sci 30:2207-2214.

Hori K, Tanaka J, Nimura M (1993) Effects of discrimination learning on the rat dopamine release: a microdialysis study. Brain Res 621:296-300.

Jolkkonen E, Pitkanen A (1998) Intrinsic connections of the rat amygdaloid complex: projections originating in the central nucleus. J Comp Neurol 395:53-72.

Kollack-Walker S, Watson SJ, Akil H (1997) Social stress in hamsters: defeat activates specific neurocircuits within the brain. J Neurosci 17:8842-8855.

Koob GF (1999) The role of the striatopallidal and extended amygdala systems in drug addiction. Ann NY Acad Sci 877:412-438.

Morimoto A, Nakamori T, Morimoto K, Tan N, Murakami N (1993) The central role of corticotrophin-releasing factor (CRF-41) in psychological stress in rats. J Physiol (Lond) 460:221-229.

Petrovich GD, Swanson LW (1997) Projections from the lateral part of the central amygdalar nucleus to the postulated fear conditioning circuit. Brain Res 763:247-254.

Pitkanen A, Stefanacci L, Farb CR, Go G-G, LeDoux JE, Amaral DG (1995) Intrinsic connections of the rat amygdaloid complex: projections originating in the lateral nucleus. J Comp Neurol 356:288-310.

Robinson TE (1984) Behavioral sensitization: characterization of enduring changes in rotational behavior produced by intermittent injections of amphetamine in male and female rats. Psychopharmacology (Berl) 84:466-475.

Rosenkranz JA, Grace AA (1999) Modulation of basolateral amygdala neuronal firing and afferent drive by dopamine receptor activation in vivo. J Neurosci 19:11027-11039.

Saper CB (1995) Central autonomic system. In: The rat nervous system (Paxinos G, ed), pp 107-135. San Diego: Academic.

Simpson L (1975) Blood pressure and heart rate responses evoked by Dand L-amphetamine in the pithed rat preparation. J Pharmacol Exp Ther 193:149-159.

Simpson L (1976) The effect of behavioral stimulant doses of amphetamine on blood pressure. Arch Gen Psychiatry 33:691-695.

Umino A, Nishikawa T, Takahashi K (1995) Methamphetamine-induced nuclear c-fos in rat brain regions. Neurochem Int 26:85-90.

Wise RA, Bozarth MA (1987) A psychomotor stimulant theory of addiction. Psychol Rev 94:469-492. 